\title{
CONTRIBUIÇÕES DA CAPACITAÇÃO E ATUAÇÃO ENQUANTO BOMBEIRO COMUNITÁRIO NA FORMAÇÃO EM ENFERMAGEM
}

\author{
CONTRIBUITION OF TRAINING AND ACTING AS COMMUNITY \\ FIREFIGHTERS IS NURSING TRAINING: AN ACCOUNT OF EXPERIENCE
}

\author{
Camila Zanesco', Daniela Aparecida dos Santos² \\ Universidade Estadual de ponta Grossa', Universidade do estado de Santa Catarina ${ }^{2}$
}

\begin{abstract}
The present study aims to report a led experience by two nursing undergraduate students that participes in the training courses for community firefighter as well as volunteers at the 6th Military Firefighters in Chapecó-SC. Considering the nursing training, many areas of study are not yet developed, this is where the extracurricular courses will enhance the training professionally and personally. The volunteer services come as help in the implementation of techiniques learned in the improvement of knowledge enabling practical action in the cases of urgencies and emergencies.
\end{abstract}

\section{Resumo}

o presente estudo objetiva relatar uma experiência de duas discentes de graduação em enfermagem, na participação nos curso de formação parabombeiros comunitários, e atuação voluntária como bombeiros comunitários no 6ㅇ Batalhão de Bombeiros Militares em ChapecóSC. Considerando a formação em enfermagem, muitas áreas de atuação são pouco exploradas, nesse sentido os cursos extracurriculares vêm no sentido de enriquecer esse processo no âmbito profissional e pessoal. O serviço voluntário vem como auxiliador, na efetivação das técnicas aprendidas, no aprimoramento dos conhecimentos, possibilitando a atuação prática frente a eventos com caráter de urgência e ou emergência. 


\section{Introdução}

O modelo que visa o atendimento a emergência no local da ocorrência, teve sua origem no Brasil por volta de 1893. Em meados de 1899 o corpo de bombeiros (CB), na então capital brasileira (Rio de Janeiro), disponibilizava pela primeira vez uma ambulância de tração animal, para realizar tal atendimento ${ }^{1}$.

$\mathrm{O}$ atendimento pré-hospitalar (APH) é aquele realizado no local da ocorrência, ganhou maior enfoque e sistematização a partir da década de 80 , se disseminando entre as instituições do CB. Com o passar dos anos surgiram diversas novas formas de resgate (exemplo: serviço de resgate aéreo), e novas formas de atuação como o baseado no modelo Francês denominado serviço de atendimento móvel de urgência (SAMU) ${ }^{1,}$ os quais se complementam e qualificam o APH.

Considerando as instituições do Corpo de Bombeiros Militar (CBM), as mesmas prestam serviços relacionados a: combate a incêndios, busca e resgate, vistorias, prevenção de sinistros, atividades técnicas, educação pública, emergências com produtos perigosos, operações aéreas, ajuda humanitária, entre outros. $\mathrm{Na}$ área da saúde, são responsáveis pelo $\mathrm{APH}$ quando há vítimas de acidentes e sinistros, desencarceramento, e atendimento emergencial a casos clínicos ${ }^{2}$.

O CBM do Estado de Santa Catarina (SC), conta com 14 batalhões e um núcleo de operações aéreas, distribuídos entre o território do Estado. No município de Chapecó, está alocado o 60 Batalhão do CBM, com 52 anos de serviços prestados a comunidade no ano de $2017^{2}$.

Por volta de 1996, surgiu o programa de Bombeiros Comunitários (BC) no Estado de SC, o qual objetiva incentivar a cultura prevencionista dentro das comunidades, através da oferta de capacitações gratuitas a cidadãos, com foco na atuação frente a situações emergenciais e de calamidade pública. Possibilitando o primeiro atendimento a vítimas, minimizando agravos e diminuindo a falta de atendimento nos locais, como consequência o programa proporciona a aproximação do CBM com a sociedade ${ }^{3}$.

Ninguém está livre de em algum momento se deparar com uma situação emergencial, nem sempre a chegada dos profissionais para o socorro é rápida, e esses momentos pósacidente são valiosos no sentido de evitar agravos e até mesmo óbitos ${ }^{4}$. Possibilitar oportunidades de conhecer, aprender e mesmo desenvolver técnicas em relação a situações de acidentes e emergências comuns em diversos cenários, é importante, para tanto é preciso que existam oportunidades de acesso a tal conhecimento ${ }^{5}$.

Considerando a inserção do discente de graduação em enfermagem no curso de capacitação disponibilizado pelos CBM, se tem uma possibilidade única de aprendizado, levando em conta que a formação acadêmica segue as delimitações das diretrizes nacionais as quais exigem uma carga horária mínima para a disciplina de primeiros socorros, impossibilitando muitas vezes a realização de atividades prática. Em relação às atividades teórico-práticas em serviços de urgência e emergência, as mesmas ocupam carga horária relativamente pequena, questão que dificulta a visualização e contato com os referidos casos, aproximação possível através da atuação voluntária na entidade do CBM.

Como profissional enfermeiro (a), deve-se tornar frequente seu papel de educador, visando à melhoria da saúde da população e todas as questões envoltas à prática educativa a qual é embasada pela Lei $7.498^{7}$. A evolução nas diversas áreas nos últimos tempos ocasionaram mudanças na sociedade e, cada vez mais, tais questões geram a demanda de se incentivar a autonomia dos indivíduos diante do seu processo saúde-doença ${ }^{6}$, papel que cabe ao profissional de enfermagem dentro das suas várias possibilidades de atuação.

Por conseguinte, a inserção de discentes de graduação em enfermagem nos cursos de formação de BC é possível e frequente, pois possibilita a atuação frente a situações com caráter de urgência e ou emergência. Neste viés através do presente relato objetiva-se demonstrar as implicações da capacitação e atuação como bombeiro comunitário em relação à formação em enfermagem.

\section{Metodologia}

Trata-se de um relato de experiência, de caráter descritivo com abordagem qualitativa, relacionado à participação nos cursos de formação e capacitação para BC, e atuação voluntária como bombeiros comunitários no 6 응 Batalhão de Bombeiros Militares em ChapecóSC, de discentes de graduação em enfermagem pela Universidade Federal da Fronteira Sul (1 discente) e, pela Universidade do Estado de Santa Catarina (1 discente), ambas situadas no município de Chapecó, Estado de Santa Catarina. A experiência contempla o 
período de outubro de 2015 a fevereiro de 2017, considerando as etapas de formação e a atuação no serviço voluntário.

\section{Resultados e Discussões}

Para se tornar bombeiro comunitário é necessário realizar uma capacitação, a qual é dividida em duas etapas (formação), sendo: 0 curso de atendimento básico a emergências (CBAE) e o Curso Avançado de Atendimento a Emergências (CAAE). A seleção para ingresso na primeira etapa ocorre por meio de prova com conteúdo previamente divulgado em edital, sendo classificados para o segundo curso os candidatos com melhor média final na etapa anterior ${ }^{3}$.

A formação e capacitação englobam diversos temas, com abordagens teóricas e práticas, são exemplos de conteúdos estudados: obstrução de vias aéreas por corpo estranho, parada cardiorrespiratória, atendimento a fraturas, luxações, entorses, contusões e hemorragias, acidente vascular encefálico, parto, febre, convulsões, insuficiência respiratória e intoxicações; Temas comumente abordados em oficinas de primeiros socorros 8 , e que contemplam a definição de APH a qual é definida como: “... toda e qualquer assistência realizada fora do âmbito hospitalar, contemplando conselhos e orientações médicas até procedimentos básicos de socorro (...) visando à manutenção da vida e à redução de sequelas (p.60)9".

Figura 1. Treinamento de combate a incêndio

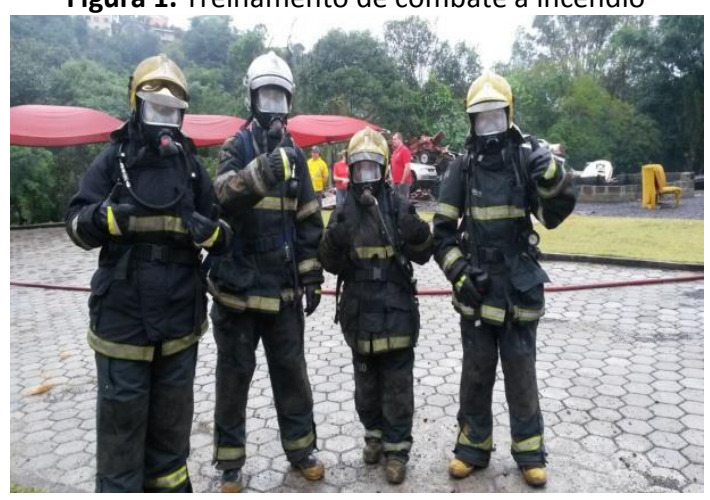

Após a formação os indivíduos que estiverem aptos poderão optar em relação ao desenvolvimento de atividades voluntárias, nas viaturas do CBMSC, com base na Lei do voluntariado $9.608 / 98^{8}$, auxiliando o efetivo militar, sendo necessário o cumprimento de uma carga horária mínima mensal (24 horas), realizada de forma contínua ou intercalada ${ }^{3}$.

Considerando a história da enfermagem com o atendimento a situações urgentes e emergenciais, sua ligação é próxima e iniciou há muito tempo, ainda nas guerras 9. Apesar do longo histórico na referida área de atuação um estudo realizado em $2010^{9}$, coletou depoimentos de enfermeiros que atuam em serviços de atendimento móvel de urgência (SAMU), em Porto Alegre, e neste trecho é possível perceber que o preparo em relação à área de $\mathrm{APH}$ ainda é deficiente: "A faculdade não nos prepara para o atendimento pré-hospitalar [...]. Eu realmente cheguei sem saber absolutamente nada, aprendi tudo no Serviço" ${ }^{\prime \prime}$.

A experiência na atuação como bombeiro comunitário por parte de estudantes de enfermagem vem no sentido de enriquecer a formação, como mostra o depoimento a seguir 10, são áreas possíveis de atuação com suas peculiaridades:

"[...], o atendimento na rua é muito diferente [...], a gente tem que lidar com o paciente, com a população, com a situação de risco da cena [...]". Tem que ter um preparo mais emocional que técnico [...] lidar com situações que estão no limiar da paciência [...] (pg 109) ${ }^{10}$."

É essencial que o atendimento seja rápido, eficaz, e resolutivo, para que a evolução do quadro da vítima seja satisfatória, evitando o máximo possível à morte e o aparecimento de sequelas, as quais são ligadas diretamente a diminuição da qualidade de vida dos indivíduos. Portanto, se requer conhecimento e preparo, os possíveis através da formação de bombeiro comunitário ${ }^{11 ; 12}$.

Ser BC possibilitou múltiplas experiências, as quais contribuíram substancialmente para o crescimento pessoal e profissional das envolvidas. Talvez a experiência não seja positiva e enriquecedora a todos os que por ela passam, neste caso particularmente, possibilitou vislumbrar a realidade das ocorrências, da demanda que lota os serviços de atendimento a urgências e emergência, e dos próprios serviços móveis de atendimento, com chamados para atendimento a casos clínicos.

Foi possível através do serviço voluntário por em prática conhecimentos e técnicas, desenvolver habilidades inerentes ao trabalho do profissional enfermeiro, vivenciar o trabalho em equipe, treinar a realização da anamnese, exame físico, lidar com a pressão imposta pelas 
ocorrências, pessoas e ou familiares próximos das vitimas, com as próprias emoções, contribuiu com a tomada rápida de decisões, desenvolvimento de olhar clínico, entre outras. A experiência constitui-se em um intercambio de saberes, o crescimento aconteceu em ambos os lados envolvidos.

Durante os atendimentos, o estudante aprende a trabalhar em equipe, pois necessita se encaixar nas rotinas do serviço assumindo suas responsabilidades, seguindo um esquema pré-estabelecido de hierarquia para o atendimento, cada indivíduo possui uma determinada função e ao final se tem uma atuação coordenada.

A atuação na prática permitiu uma autoavaliação enquanto estudantes, pois, possibilitando a visualização das falhas, dificuldades e oportunizando momentos para a correção, melhoramento das mesmas. Adiante compor um serviço conhecido pela sua excelência, e que tem o reconhecimento da comunidade sobre sua importância, constitui-se como oportunidade única, uma auto-realização circundada pelo sentimento de dever cumprido.

\section{Conclusões}

A participação de estudantes de cursos de graduação na área da saúde em capacitações que englobam atendimento pré-hospitalar (APH), consiste em uma experiência exitosa e produtiva, contribuinte para a formação pessoal e profissional dos envolvidos.

A partir da experiência vivenciada, considerando os respectivos benefícios, aprendizado e possibilidades geradas, sugere-se a disponibilização de cursos de capacitação em âmbito de extensão pela universidade aos seus estudantes e funcionários, pois como apontado todos estão susceptíveis a se depararem com situações emergências que requerem atuação, adiante se considera pertinente a reestruturação e ou adição de disciplinas ofertadas nos cursos de graduação que contemplem tais conteúdos.

\section{Referências}

1. Martins PPS, Prado MLD. Enfermagem e serviço de atendimento pré-hospitalar: descaminhos e perspectivas. Rev Bras Enferm. 2003; 56(1): 71-75.

2. Corpo de bombeiros militar de Santa
Catarina [internet]. Atividades. Disponível em: https://portal.cbm.sc.gov.br/index.php/institucio nal/atividades.

3. Corpo de bombeiros militar de Santa Catarina [internet]. Bombeiros comunitários. Disponível em: https://portal.cbm.sc.gov.br/index.php/bombeiri ro-comunitario.

4. Tinoco VDA, Reis MMT, Freitas LN. O enfermeiro promovendo saúde como edu-cador escolar: Atuando em primeiros socorros. Revista Transformar. 2014; 6: 104-113.

5. Macena RHM, Braga DKAP, Amaral LBDM, Souza DLDL, Rodrigues BN, Vascon-celos TBD, et al. Avaliação educativa de promoção da saúde baseado em compe-tências nas ações de primeiros socorros na construção civil: relato de experiência da fisioterapia. Revista de Ciências Médicas e Biológicas.2014; 13 (1): 64-71.

6. Pergola AM, Araujo IEM. O leigo em situação de emergên-cia. Rev Esc Enferm USP. 2008; 42(4):769-76.

7. Oliveira MRD, Leonel ARA, Montezeli JH, Gastaldi AB, Martins EAP, Caveião C. Concepção de graduandos de enfermagem sobre a prática de educação em saúde em primeiros socorros. Revista da Rede de Enfermagem de Nordeste. 2015; 16(2): 150-158.

8. Veronese AM, Oliveira DLLCD,Nast K, Rosa IMD.Oficinas de primeiros socorros: Relato de experiência. Rev Gaúcha Enferm. 2010; 31(1):179-82.

9. Maia RM, Júnior JG, Lima EP, Campos W, Jovino EM, Fernandes FF, et al. Co-nhecimentos em Atenção Pré-Hospitalar e Suporte Básico de Vida por Estudantes Recém-ingressos de Medicina. Revista brasileira de educação médica. 2014; 38 (1): 59-64.

10. Cardoso $\mathrm{FH}$, Paiva [internet]. LEI № 9.608, DE 18 DE FEVEREIRO DE 1998. Disponível em:http://www.planalto.gov.br/ccivil_03/leis/L9 608.htm.

11. Romanzini E M, Bock LF. Concepções e sentimentos de enfermeiros que atuam no atendimento pré-hospitalar sobre a prática e a formação profissional. Rev. Latino-Am. Enfermagem. 2010; 18(2): 105-112.

12. Leitão FBP, Sousa MCD, Birolini D, Vieira JE. Prevention and Life Support in Case of Trauma and Cardiovascular Diseases: an Educational Program. Revista brasileira de educação médica. 2007; 32 (4): 419-423. 


\section{Endereço para Correspondência}

Universidade Estadual de ponta Grossa - UEPG

Rua Cel. Bitencourt, 689 - Centro, Ponta Grossa $P R$

CEP.: 84010-290

e-mail: camila_zanesco@hotmail.com

Recebido em 10/05/2017

Aprovado em 25/07/2017

Publicado em 01/12/2017 